\title{
The Csk Homologous Kinase, Chk, Binds Tyrosine Phosphorylated Paxillin in Human Blastic T Cells ${ }^{1}$
}

\author{
Svetozar Grgurevich, Anwar Mikhael, and Daniel W. McVicar ${ }^{2}$ \\ Laboratory of Experimental Immunology, Division of Basic Sciences, National Cancer Institute, \\ $\mathrm{NCl}-\mathrm{FCRDC}$, Frederick, Maryland 21702-1201
}

In determining the role of Chk in T cell signaling, we have focused on its protein-protein interactions. We detected a tyrosine phosphoprotein that coimmunoprecipitated with Chk from pervanadate stimulated human blastic T cells. Subsequent Western blot analysis identified this tyrosine phosphoprotein as paxillin. Paxillin, a cytoskeletal protein involved in focal adhesions, was first identified as a v-Src substrate in transformed fibroblasts. Interestingly, Chk specifically bound tyrosine phosphorylated paxillin. Consistent with our in vivo data, Chk and paxillin were observed to localize in similar cellular regions prior to and following stimulation. Using GST fusion proteins, we determined that the Chk SH2 domain, not the SH3 domain, bound tyrosine phosphorylated paxillin. Specifically, paxillin bound to the FLVRES motif of the Chk SH2 domain. Using Far Western analysis, we revealed that the Chk SH2 domain directly associates with tyrosine phosphorylated paxillin. Finally, $\mathrm{p}^{\mathrm{chk}}$ expression in Csk-deficient mouse embryo fibroblasts decreased total phosphotyrosine levels of paxillin, implying a physiological role for Chk. These studies provide important insight into the role of Chk in tyrosine mediated signaling, as well as T cell physiology.

Key Words: kinase; Chk; Src; paxillin.

The Src family of cytoplasmic tyrosine kinases plays a critical role in mitotic control, cell-cell communica-

\footnotetext{
${ }^{1}$ The U.S. Government right to retain a nonexclusive, royalty-free license in and to any copyright covering the paper, for governmental purposes, is acknowledged. The contents of this publication do not necessarily reflect the views or policies of the Department of Health and Human Services, nor does mention of trade names, commercial products, or organizations imply endorsement by the U.S. Government.

${ }^{2}$ To whom correspondence should be addressed at BIdg 560, Rm 31-93, Laboratory of Experimental Immunology, Division of Basic Sciences, Frederick Cancer Research and Development Center, National Cancer Institute, Frederick, MD 21702. Fax: 301-846-1673. E-mail: MCVICAR@NIH.GOV.
}

tion, cytoskeletal organization, and signaling (1). Src family kinase activity is inhibited by phosphorylation of a conserved, carboxy-terminal tyrosine (2). Conversely, dephosphorylation of this site results in activation of intrinsic kinase activity (3). Mutation of this conserved tyrosine to phenylalanine constitutively activates c-Src and renders it oncogenic (4). Csk, c-terminal Src kinase, phosphorylates the conserved inhibitory tyrosine of Src family kinases, thereby re pressing their kinase activity (5-11).

Recently, several groups identified a second member of the Csk family, known as Chk, Csk homologous kinase (12-17). The Chk gene, previously termed Lsk, Hyl, Matk, Ntk, Ctk, and Batk, codes for two distinct proteins, $\mathrm{p} 52^{\mathrm{chk}}$ and $\mathrm{p} 57^{\mathrm{chk}}$. The predominant Chk isoform expressed in mouse, 52 kDa, lacks $40 \mathrm{~N}$-terminal amino acids present in the predominant human isoform, $57 \mathrm{kDa}$, as a result of alternative splicing (18). Chk and Csk are structurally related genes $(12,19)$. Both Chk isoforms, like Csk, contain Src homology (SH) domains 2 and 3, as well as a Src family catalytic domain (SH1). Similar to Csk, neither Chk protein contains a myristoylation signal residue, nor has the autophosphorylation or carboxyl-terminal tyrosine residues typical of Src family kinases. Additionally, Chk phosphorylates the inhibitory carboxyl-terminal tyrosine of several Src family kinases, including Lck, Fyn, c-Src, and Lyn, in vitro or in a yeast co-expression system $(12,13,20,21)$. Despite the structural and enzymatic similarities, differences exist between Chk and Csk. Chk expression, unlike the ubiquitous expression of Csk, is limited to neuronal and hematopoietic cells. Chk expression, unlike Csk, is regulated by IL-4 and I L-13 in human monocytes and by stem cell factor in the human megakaryoblastic cell line MO7e $(22,23)$. Furthermore, Chk expression is induced in T cells upon activation, whereas Csk is constitutively expressed (14).

Because of the differences in expression, $\mathrm{T}$ cells provide an attractive model for dissecting the individual roles of Chk and Csk. The Src family is critical in T cell 
physiology (24). Lck and Fyn are involved in the signal transduction of $T$ cell receptor, TcR, mediated activation $(25,26)$. In addition, Lck is also crucial for thymic precursor development into differentiated $T$ cell types (27). Csk overexpression in an antigen-specific T cell line, BI-141, inhibits TCR induced protein phosphorylation and lymphokine secretion, presumably by inhibiting Lck and Fyn $(28,29)$. We and others have demonstrated that Chk does not appear to be involved in TcR signal transduction $(30,31)$. These observations imply a unique role for Chk in T cell signaling.

In elucidating the role of Chk in T cell signaling, we have focused on its protein-protein interactions. The specificity of these transient protein-protein interactions is mediated by conserved protein modules, such as the $\mathrm{SH} 2$ and $\mathrm{SH} 3$ domains. The $\mathrm{SH} 2$ domains bind phosphorylated tyrosine residues (32), whereas, SH3 domains bind proline-rich sequences (33). In this report, we immunoprecipitated a tyrosine phosphorylated protein with Chk in pervanadate stimulated, human blastic $T$ cells. Subsequent experiments have identified the coprecipitated protein as paxillin, a cytoskeletal protein first identified as a v-Src substrate (34). GST fusion proteins expressing the Chk protein binding domains were used to determine which region interacted with tyrosine phosphorylated paxillin. Lastly, Csk-deficient mouse embryo fibroblasts, ME Fs, were transfected with Chk to determine if paxillin was affected in vivo.

\section{MATERIALS AND METHODS}

Cells, cell culture, and antibodies. After informed consent, T cells were prepared from peripheral blood of healthy volunteers as previously described (35). T cells, greater than $90 \%$ purity, were activated in complete medium with human recombinant I L-2 (1000 I.U./ml) for 4 days in culture at a density of $2 \times 10^{6} \mathrm{cell} / \mathrm{s} / \mathrm{ml}$. Complete medium consisted of RPMI-1640 supplemented with $10 \%$ fetal bovine serum, $2 \mathrm{mM} \mathrm{L}$-glutamine, and $1 \%$ penicillin-streptomycin. Simian virus (SV) 40 immortalized Csk-deficient, MEFs were obtained from Dr. Akira Imamoto (10). MEFs were propagated in Dulbecco's minimal essential medium supplemented with $10 \%$ fetal bovine serum. T cells and MEFs were cultured at $37^{\circ} \mathrm{C}$ in $5 \% \mathrm{CO}_{2}$ incubators. The rabbit polyclonal antibody raised against Chk was obtained from Santa Cruz Biotechnology (Santa Cruz, CA). This antibody was generated against the predicted carboxyl-terminal (amino acids 449-465) of the Lsk protein. The $\alpha$-paxillin monoclonal antibody was obtain from Zymed, Inc. (San Francisco, CA). The $\alpha$-phosphotyrosine monoclonal antibody, 4G10, and the $\alpha$-GST and $\alpha$-Lck polyclonal antibodies, were purchased from U pstate Biotechnology Inc. (Lake Placid, NY). Antibody against Csk was kindly provided by Dr. Marietta Harrison (Purdue University).

Immunoprecipitation, electrophoresis, and Western blot analysis. Human blastic T cells were incubated in the presence or absence of pervanadate as described (36). Csk-deficient and $\mathrm{p} 52^{\mathrm{Chk}}$ transfected MEFs were scraped from $10 \mathrm{~cm}$ plates prior to lysis. Cells were lysed in buffer containing 1\% NP-40, $150 \mathrm{mM} \mathrm{NaCl}, 50 \mathrm{mM}$ Hepes $(\mathrm{pH}$ 7.1), $10 \mathrm{mM}$ EDTA, $0.4 \mathrm{mM} \mathrm{Na} \mathrm{VO}_{4}, 10 \mathrm{mM} \mathrm{NaF}, 1 \mathrm{mM}$ PMSF, 10 $\mu \mathrm{g} / \mathrm{ml}$ leupeptin, $10 \mu \mathrm{g} / \mathrm{ml}$ aprotinin, and $0.7 \mu \mathrm{g} / \mathrm{ml}$ pepstatin A. Cell lysates were clarified by centrifugation for 15 minutes at $15,000 \mathrm{rpm}$ at $4^{\circ} \mathrm{C}$. Lysates from $1 \times 10^{8} \mathrm{~T}$ cells or $100 \mu \mathrm{g}$ total protein (BCA protein assay, Pierce, Rockford, IL) from MEF s were immunoprecipi- tated with appropriate antibody coupled to protein A ( $\alpha$-Chk) or G ( $\alpha$-paxillin) sepharose for one hour at $4^{\circ} \mathrm{C}$. I mmunoprecipitates were washed three to six times with lysis buffer. Excess competing peptide was used in Chk immunoprecipitations where noted. Bound protein was then eluted with Laemmli sample buffer and separated on $10 \%$ SDS PAGE. After electrophoretically transferring the proteins to I mmobilon membranes (37), the resulting blots were probed with the appropriate antibody. The antibodies used in these studies included $\alpha$-phosphotyrosine, $\alpha$-paxillin, and $\alpha$-Chk. Enhanced chemiluminescence (ECL [Amersham Corp.]) was used for antibody detection as described by the manufacturer. In experiments involving MEFs, bands were quantified using laser densitometry. Blots were occasionally stripped of bound antibodies by incubation in $62.5 \mathrm{mM}$ Tris- $\mathrm{HCl}$ (pH 6.8), $100 \mathrm{mM} \beta$-mercaptoethanol, and 2\% SDS for 30 minutes at $50^{\circ} \mathrm{C}$. The stripped blots were washed extensively in TBS, blocked, and probed again with an appropriate antibody.

Subcellular fractionation. Pervanadate stimulated and unstimulated blastic $\mathrm{T}$ cells were incubated for 15 minutes in hypotonic buffer (10 mM Tris pH 7.4, 2 mM EDTA pH 8.0, supplemented with protease and phosphatase inhibitors as described above). The membranes were mechanically broken using a Wheaton Dounce homogenizer. Cell lysis was confirmed by staining with trypan blue. After adjusting lysate concentration to $150 \mathrm{mM} \mathrm{NaCl}$, nuclei and intact cell membrane were removed by two successive centrifugations at $1,000 \times \mathrm{g}$ for 5 minutes. Supernatants were then separated into soluble (S100) and particulate (P100) fractions by ultracentrifugation at $100,000 \times \mathrm{g}$ for 30 minutes. The various fractions were extracted in Laemmli sample buffer; particulate fractions were washed once with hypotonic buffer prior to extraction. Fractions containing equivalent cell numbers were resolved on either 8 or $10 \%$ SDS PAGE and immunoblotted with either $\alpha$-Chk or $\alpha$-paxillin re spectively. The validity of the cell fractionation procedure was confirmed by blotting with $\alpha$-Lck and $\alpha$-Csk (data not shown).

cDNAs and constructs. The murine p52 $2^{\mathrm{chk}} \mathrm{cDNA}$ was obtained from Dr. Christopher J arvis $(12,18)$. The cDNA was digested by EcoRI and Xhol and cloned into the vector pCDNA 3.1/Zeo(+) (Invitrogen). The constructs were transfected in the MEFs with LipofectAMINE Reagent as described by the manufacturer (Life Technologies, Gaithersburg MD). Transfected cells were selected by growth in Dulbecco's minimal essential medium containing 10\% fetal bovine serum and Zeomycin.

Bacterial expression plasmids encoding GST-Chk SH2, GST-Chk SH3, and GST-Chk SH2-SH3 were constructed by subcloning PCRgenerated Bam $\mathrm{H} 1$ fragments, using Chk CDNA as the template, into pGEX-3X vectors. GST-Chk SH2 was generated with the following oligonucleotides: 5'-GATCGGATCCCCAAGCTCAGCCTCATGCCG-3' (forward primer) and 5'-GATCGGATCCGACTTGGTCCCGTGTTTCCG-3' (reverse primer). GST-Chk SH3 was generated with the following oligonucleotides: 5'-GATCGGATCCTCTCAGCCAGGATGCCAACG-3' (forward primer) and 5'-GATCGGATCCGGCATGAGGCTGAGCTTGGG-3' (reverse primer). GST-Chk SH2-SH3 was generated with the forward primer used to generate GST-Chk SH3 and the reverse primer used to generate GST-Chk $\mathrm{SH} 2$.

To make the mutant GST-Chk SH2 (S149C) fusion protein, sitedirected mutagenesis was performed as described elsewhere (38). The mutagenic primer used for S149C was 5'-GTGCGGGAGTGCGCACGCCACCCCG-3'. Construction of all the plasmids was verified by double-stranded sequencing.

Preparation of the GST fusion proteins. After transformation of GST constructs into the J M 105 strain of Escherichia coli, log-phase cultures were induced for two hours at $37^{\circ} \mathrm{C}$ with $1.0 \mathrm{M}$ isopropyl $\beta$-D-thiogalactopyranoside (IPTG). Cells were sonically lysed in phosphate buffered saline, $1 \%$ Triton X-100 and centrifuged. Clarified supernatants were incubated with glutathione Sepharose-4B for 60 minutes at $4^{\circ} \mathrm{C}$. Bound fusion proteins were washed extensively with lysis buffer and eluted with $10 \mathrm{mM}$ reduced glutathione. Proteins were dialyzed against phosphate buffered saline, 10\% glycerol, 
and $10 \mathrm{mM}$ EDTA and concentrated using microconcentrators (Amicon, Beverly, MA). Protein concentration was determined (BioRad, Hercules, CA), and the proteins were stored at $-70^{\circ} \mathrm{C}$ until further use. Protein purity was checked using SDS-PAGE and subsequent Coomassie Blue staining.

GST in vitro binding assay. Two $\mu$ g GST or equimolar amounts of each purified GST fusion proteins were bound to glutathioneagarose beads for 60 minutes at $4^{\circ} \mathrm{C}$, then washed in PBS. Pervanadate stimulated and unstimulated blastic $T$ cells were lysed with the same lysis buffer used in immunoprecipitations. Cell lysates were incubated with bound GST fusion proteins for one to two hours at $4^{\circ} \mathrm{C}$, and washed three times with modified RIPA buffer ( $1 \%$ Triton X-100, 50 mM Hepes, pH 7.1, 1\% sodium deoxycholate, 0.1\% SDS, $150 \mathrm{mM} \mathrm{NaCl}, 10 \mathrm{mM}$ EDTA, and 10\% glycerol, and supplemented with the protease and phosphatase inhibitors described above). The blots were probed with $\alpha$-paxillin, and visualized by enhanced chemiluminescence.

Binding with GST fusion proteins (Far Western). Paxillin immunoprecipitates were resolved by $10 \%$ SDS-PAGE and transferred to Immobilon membranes. Replica blots were initially blocked with TBS - 2.5\% BSA for 60 minutes at room temperature. The blots were probed with either $5 \mu \mathrm{g} / \mathrm{ml}$ of purified GST or equimolar concentrations of purified GST-SH2 and GST-S149C, respectively. After a 60 minute incubation at room temperature, the blots were washed in TBS - $0.1 \%$ Tween 20 . The blots were then probed with a polyclonal $\alpha$-GST antibody. Following washing, blots were incubated with horseradish peroxidase conjugated $\alpha$-rabbit antibody, washed, and detected by enhanced chemiluminescence.

\section{RESULTS}

\section{Chk Copreci pitates a Tyrosine Phosphoprotein in Human Blastic T Cells}

The role of Chk in T cell signaling is currently unknown. To detect novel Chk protein interactions, we attempted to coimmunoprecipitate tyrosine phosphoproteins from stimulated human blastic $T$ cells. Initially, human peripheral blood $T$ cells were activated with IL-2 (as described in Materials and Methods) to induce Chk expression. The activated T cells were then stimulated with pervanadate, a nonspecific inducer of tyrosine phosphorylation. A tyrosine phosphoprotein, approximately 70-75 kDa, coimmunoprecipitated with Chk following pervanadate stimulation (Fig. 1A). The band was not present following peptide competition. The blots were stripped and reblotted with $\alpha$-Chk; thereby verifying both equivalent loading and the efficacy of the peptide competition (Fig. 1B). This experiment revealed the first protein association of Chk in $\mathrm{T}$ cells.

\section{Coprecipitation of Tyrosine Phosphorylated Paxillin with Chk}

We then attempted to identify the Chk associated tyrosine phosphoprotein. Our search focused on Src substrates. Of the prominent tyrosine phosphoproteins in V-Src transformed cells, tyrosine phosphorylated paxillin has a size corresponding to the Chk associated protein (34). Furthermore, Csk associates with paxillin (39).
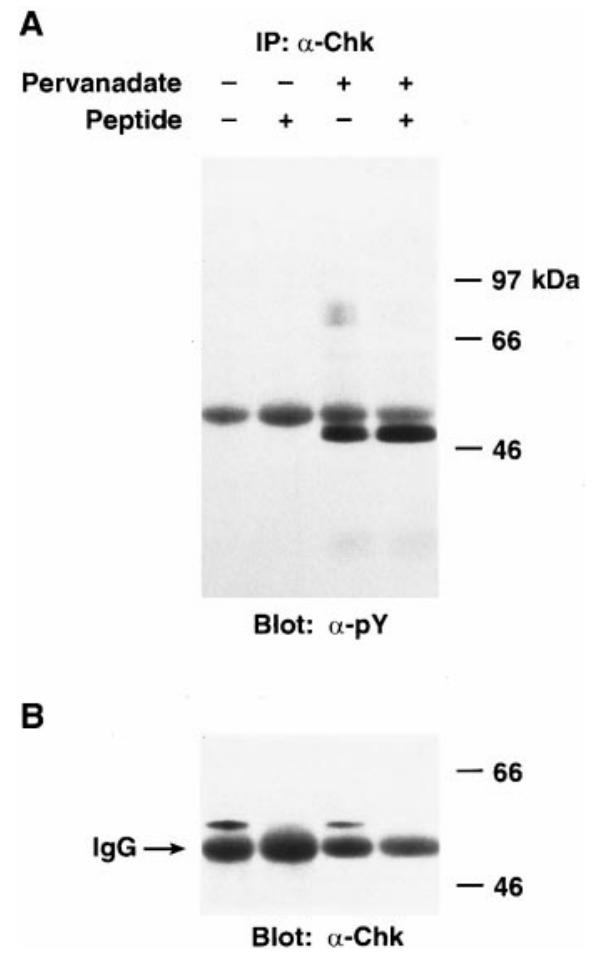

FIG. 1. Coprecipitation of a tyrosine phosphoprotein with Chk in human blastic $T$ cells. Human blastic $T$ cells were unstimulated and stimulated with pervanadate. A. Lysates ( $1 \times 10^{8}$ cells) were immunoprecipitated with an $\alpha$-Chk antibody (with and without competing peptide) and resolved using SDS-PAGE. Subsequent Western blot analysis was performed using an $\alpha$-phosphotyrosine antibody. B. The above-mentioned blot was stripped. Western blot analysis was then performed using an $\alpha$-Chk antibody.

To determine whether the Chk associated protein was in fact paxillin, we used Western blot analysis. We immunoprecipitated Chk in unstimulated and pervanadate stimulated $\mathrm{T}$ cells, and immunoblotted using $\alpha$-paxillin. Paxillin appeared to coimmunoprecipitate with Chk from both stimulated and unstimulated cells (Fig. 2A). Additional experiments determined that the $70 \mathrm{kDa}$ binding from unstimulated cells was nonspecific (data not shown). In parallel, the cell lysates were immunoprecipitated with $\alpha$-paxillin, and immunoblotted with $\alpha$-phosphotyrosine to confirm that paxillin is tyrosine phosphorylated (Fig. 2B).

\section{Subcellular Fractionation of Chk and Paxillin}

Since tyrosine phosphorylated paxillin and Chk bind, they should also co-localize in similar cellular regions. Cellular localization of Chk and paxillin was determined by subcellular fractionation studies. Consistent with the coimmunoprecipitation studies, Chk and paxillin were located in similar cellular regions, in both the S100 (cytosolic) and the P100 (membrane) fractions, prior to and following stimulation (Fig. 3). Also, greater Chk and paxillin protein levels were lo- 


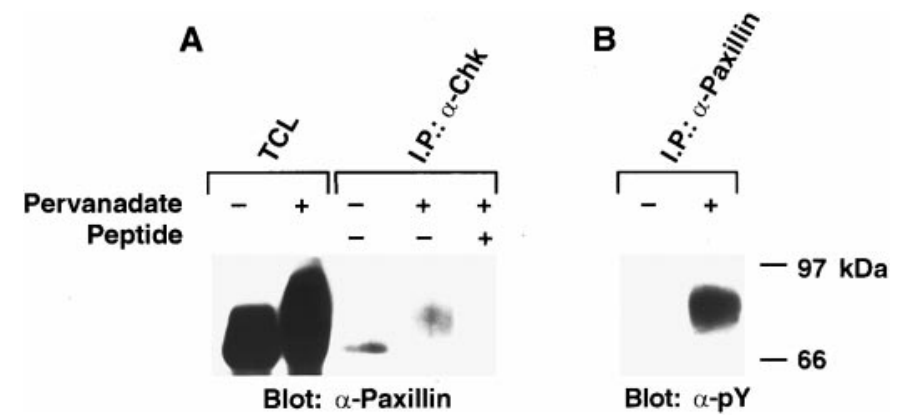

FIG. 2. Coprecipitation of tyrosine phosphorylated paxillin with Chk in human blastic T cells. Human blastic T cells were unstimulated and stimulated with pervanadate. A. Lysates $\left(1 \times 10^{8}\right.$ cells $)$ were immunoprecipitated with an $\alpha$-Chk antibody (with and without competing peptide) and resolved using SDS-PAGE. Subsequent Western blot analysis was performed using an $\alpha$-phosphotyrosine antibody. B. The above-mentioned blot was stripped. Western blot analysis was then performed using and $\alpha$-Chk antibody.

cated in the stimulated P100 fractions than the unstimulated P100 fractions. This implies an apparent migration of the two proteins following stimulation. However, the specific cellular region where Chk and paxillin associate is currently unknown. The fractions were also immunoblotted with $\alpha$-Lck and $\alpha$-Csk antisera as controls for the fractionation procedure and response to pervanadate (data not shown).

\section{The Chk SH2 Domain Binds Tyrosine}

Phosphorylated Paxillin

We next examined which Chk region binds tyrosine phosphorylated paxillin. The Chk protein contains $\mathrm{SH} 2$ and $\mathrm{SH} 3$ protein domains. GST fusion proteins expressing the Chk SH3, SH2, and the SH3-SH2 domains were generated, and used in an in vitro binding assay. Paxillin from unstimulated cells did not bind the fusion proteins. Whereas, paxillin from pervanadate stimulated cells coprecipitated only with the Chk SH3$\mathrm{SH} 2$ and $\mathrm{SH} 2$ domains (Fig. 4A). Figure 4B demonstrated equivalent loading of the respective fusion proteins. Since paxillin did not bind the $\mathrm{SH} 3$ domain and paxillin affinity was comparable between the $\mathrm{SH} 3-\mathrm{SH} 2$ and the $\mathrm{SH} 2$ fusion proteins, the $\mathrm{Chk} \mathrm{SH} 3$ domain did not appear to be involved in binding paxillin. Thus, of the known Chk protein binding regions, the $\mathrm{SH} 2$ domain mediates paxillin association.

\section{The Conserved SH2 Domain FLVRES Sequence \\ Is Required for Chk Binding to Tyrosine \\ Phosphorylated Paxillin}

Subsequent experiments were performed to determine the Chk SH2 domain region or motif that binds tyrosine phosphorylated paxillin. Many SH2 mediated interactions involve phosphotyrosine; however, numerous observations have reported non-phosphotyrosine mediated binding to $\mathrm{SH} 2$ domains. Mutations were made in the conserved FLVRES motif of the GST SH2 constructs that eliminate in vitro binding to phosphotyrosine containing proteins $(40,41)$. As expected, the S149C mutation completely abolished binding to tyrosine phosphorylated paxillin (Fig. 5). These data indicate that $\mathrm{Chk} \mathrm{SH} 2$ domain binding of tyrosine phosphorylated paxillin is dependent on the FLVRES motif; thereby, suggesting a phosphotyrosine dependent interaction.

\section{The Chk SH2 Domain Directly Binds Tyrosine Phosphorylated Paxillin}

Since paxillin has been shown to associate with Csk (39) as well as other proteins, Chk SH2 binding to paxillin may result from either a direct interaction or through intermediate protein(s). To determine whether the Chk $\mathrm{SH} 2$ domain directly interacts with tyrosine phosphorylated paxillin, we performed Far Western analysis. Paxillin was immunoprecipitated from unstimulated and pervanadate stimulated T cells and subsequently probed with either purified GST, GST-Chk SH2, or the GST-Chk SH2 mutant, S149C (Fig. 6A). The Chk SH2 domain, in contrast to GST alone or the GST-S149 mutant, detected phosphotyrosine containing paxillin from stimulated cells. The blots were stripped and reprobed with an $\alpha$-paxillin antibody to confirm the presence of paxillin (Fig. 6B). Thus, Chk, via its $\mathrm{SH} 2$ domain, binds directly to tyrosine phosphorylated paxillin.

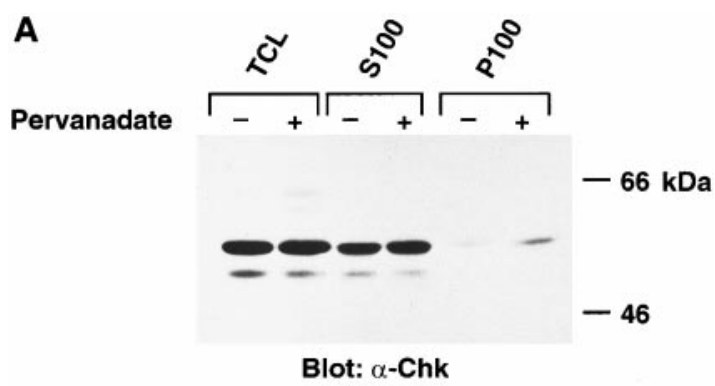

B

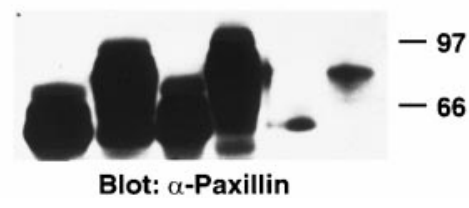

FIG. 3. Subcellular fractionation of Chk and paxillin in human blastic T cells. Human blastic T cells were treated in the absence and presence of pervanadate. Cells were lysed and subsequently separated into soluble (S100) and particulate (P100) fractions. Total cell lysate (TCL), S100, and P100 fractions from approximately $1 \times 10^{7}$ cells were resolved using SDS-PAGE. Western blot analysis was performed using either an $\alpha$-Chk antibody (A) or an $\alpha$-paxillin antibody (B). 
A

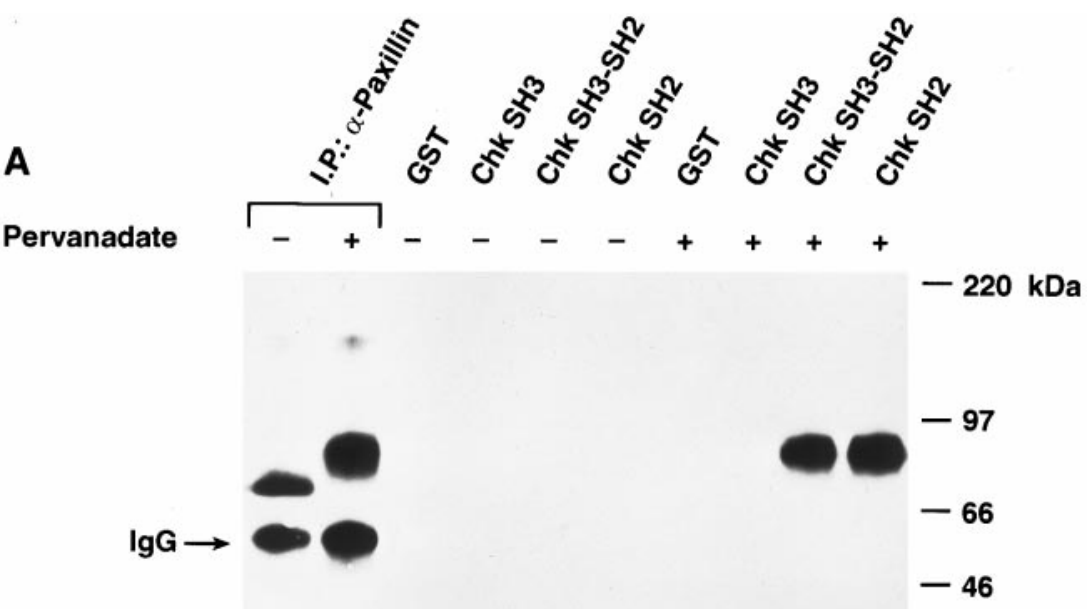

$-30$

$-21.5$

Blot: $\alpha$-Paxillin

B

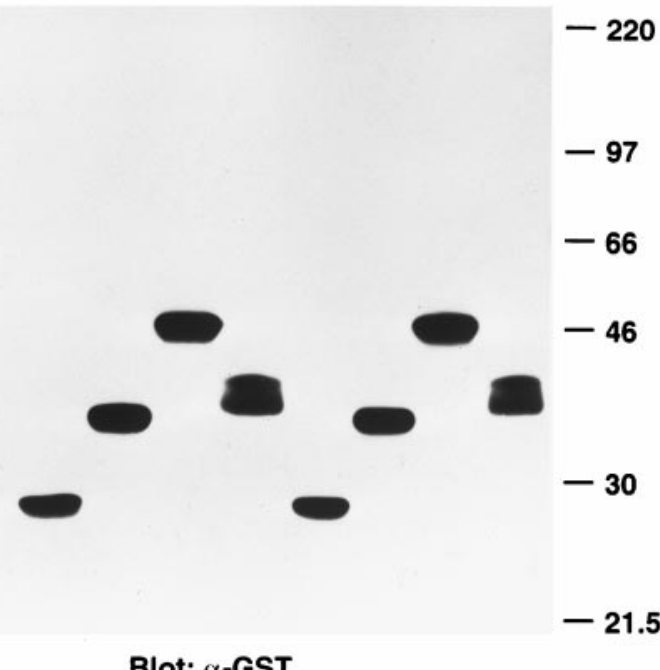

FIG. 4. The Chk SH2 domain binds tyrosine phosphorylated paxillin. Human blastic $\mathrm{T}$ cells were unstimulated and stimulated with pervanadate. A. Lysates ( $2 \times 10^{7}$ cells) were incubated with the following GST fusion proteins: GST alone, Chk SH3, SH3-SH2, and SH2 Concurrent with the binding assay, lysates $\left(1 \times 10^{6}\right.$ cells) were also immunoprecipitated with $\alpha$-paxillin. The samples were resolved using SDS-PAGE, and immunoblotted with $\alpha$-paxillin. B. The above-mentioned blot was stripped and then immunoblotted with $\alpha$-GST.

Chk Expression in Csk Deficient Cells Regulates Paxillin Phosphotyrosine Levels

Following the demonstration that Chk directly associates with tyrosine phosphorylated paxillin, we examined whether Chk may regulate paxillin phosphotyrosine levels. Csk-deficient mouse embryo fibroblasts (MEFs) were stably transfected with $\mathrm{p} 52^{\text {chk }}$. MEFs transfected with vector alone and MEFs expressing various levels of Chk were lysed and paxillin was immunoprecipitated. Paxillin phosphotyrosine levels were determined first by immunoblotting with $\alpha$-phosphotyrosine antibodies, stripping the blots, and then normalizing the values to paxillin levels following immunoblotting with $\alpha$-paxillin antibodies. The analysis reveals that Chk expression reduces paxillin phos- 


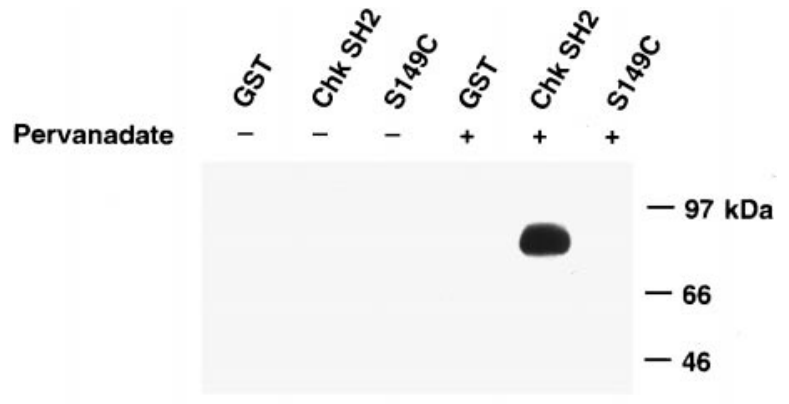

Blot: $\alpha$-Paxillin

FIG. 5. Tyrosine phosphorylated paxillin binds to the FLVRES sequence of the Chk $\mathrm{SH} 2$ domain. Human blastic T cells were unstimulated and stimulated with pervanadate. Lysates $\left(2 \times 10^{7}\right.$ cells $)$ were incubated with the following GST fusion proteins: GST alone, Chk SH2, and S149C (Chk SH2 mutant). The samples from the binding assay were resolved via SDS-PAGE, and subsequently immunoblotted with $\alpha$-paxillin.

photyrosine levels; furthermore, this regulation is dependent on Chk expression levels (Fig. 7).

\section{DISCUSSION}

The physiological role of Chk is currently unknown. In addition, little is known about the role of Chk in signaling, specifically its protein-protein interactions.

A

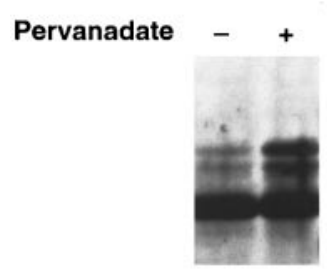

I.P.: $\alpha$-Paxillin

Blot: GST
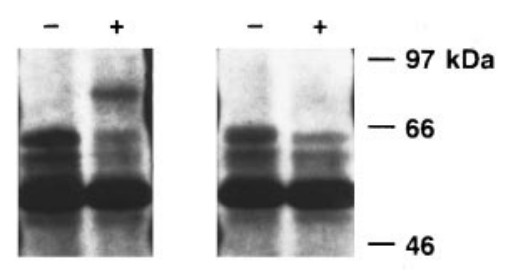

B

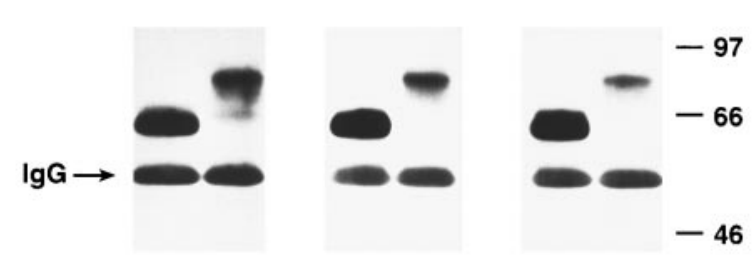

Blot: $\alpha$-Paxillin

FIG. 6. Direct binding of the Chk $\mathrm{SH} 2$ domain to tyrosine phosphorylated paxillin. Human blastic $T$ cells were unstimulated and stimulated with pervanadate. A. Lysates $\left(1 \times 10^{6}\right.$ cells) were immunoprecipitated with $\alpha$-paxillin and resolved using SDS-PAGE. Far Western analyses were then performed using the following GST fusion proteins: GST alone, Chk SH2, and S149C (Chk SH2 mutant). $B$. The above-mentioned blots were stripped and immunoblotted with $\alpha$-paxillin.

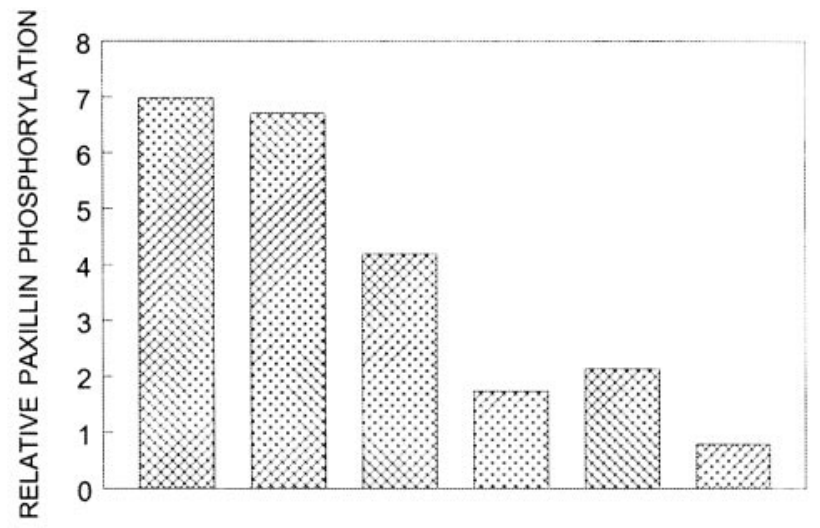

p52

FIG. 7. Chk expression in Csk-deficient cells regulates paxillin phosphotyrosine levels. Csk-deficient MEF clones, transfected with vector alone and $\mathrm{p} 52^{\mathrm{Chk}}$, were lysed and paxillin was immunoprecipitated (Top). Following SDS-PAGE, paxillin phosphotyrosine content was determined by Western blotting using an $\alpha$-phosphotyrosine antibody and quantified by laser densitometry. After stripping the blots, phosphotyrosine levels were normalized to total paxillin levels. Total paxillin levels were determined by Western blotting using an $\alpha$-paxillin antibody and quantified by laser densitometry. (Bottom) Lysates from the various clones were resolved using SDS-PAGE. Western blot analysis was performed using an $\alpha$-Chk antibody.

Chk has been shown to interact only with the receptors c-Kit and ErbB-2/neu $(42,43)$. Here we report a novel interaction involving Chk and paxillin.

In this study, we demonstrate the physical association of paxillin with Chk by coimmunoprecipitation experiments using human blastic T cells. This in vivo interaction required the tyrosine phosphorylation of paxillin. Our finding that Chk and paxillin are located in similar cellular regions in human blastic $\mathrm{T}$ cells, both prior to and following stimulation, supports the in vivo data. Furthermore, our subcellular localization studies revealed a Chk presence primarily in the cytosolic fraction, with low levels present in the particulate (membrane) fraction. Following stimulation, greater Chk levels were present in the particulate fraction, implying a translocation from the cytoplasm to the membrane. Previous reports have shown Chk in the cytosolic fractions of Chk transfected NIH 3T3 fibroblasts and of Src-Chk (Chk tagged with the Src membrane targeting signal) transfected $\mathrm{BI}-141$ murine $\mathrm{T}$ cell hybridomas $(18,31)$. Whereas, others have reported Chk presence in both the cytosolic and particulate fractions of resting human platel ets and Chk overexpressing Dami cells $(21,44)$. Chk presence in the particulate fractions, therefore, appears independent of stimuli or of cell lineage. Rather, Chk presence in the particulate fraction may result from Chk association with either a membrane bound protein or a protein 
which then migrates to the cell membrane. Further studies examining Chk migration should clarify this issue.

We have also demonstrated tyrosine phosphorylated paxillin binding to the $\mathrm{Chk} \mathrm{SH} 2$ domain by coprecipitation studies using GST recombinant proteins. The Chk SH3 domain did not bind paxillin, nor did it enhance or stabilize $\mathrm{SH} 2$ binding to paxillin. Furthermore, the $\mathrm{SH} 2$ mediated interaction with tryosine phosphorylated paxillin was destabilized when Serine $^{144}$ in the conserved SH2 domain FLVRES sequence was mutated. The phosphate moiety of the tyrosine residue binds arginine in the FLVRES motif (45, 46). Our mutation studies revealed that paxillin binds to the Chk SH2 FLVRES sequence and suggests that this is a phosphotyrosine dependent interaction. Our gel overlay (Far Western) studies have determined that the Chk SH2 domain binding to tyrosine phosphorylated paxillin is direct, and not mediated by a third protein.

Csk, like Chk, physically associates with tyrosine phosphorylated paxillin via its SH2 domain (39). Chk and Csk binding to paxillin may suggest functional redundancy. However, due to differing roles of Chk and Csk in T cells, they may independently associate with paxillin resulting in separate and distinct functions. Independent interactions with paxillin may result from activation of different receptors, thereby involving receptor specific Csk family members. Chk, unlike Csk, localizes to the cytoskel eton (21). As a result, Chk and Csk interactions with paxillin might be restricted to specific cellular regions. Finally, since paxillin is phosphorylated on tyrosine residues at positions 31, 118, and possibly 40 (47), Chk and Csk may physically associate with paxillin at different phosphotyrosine sites.

Csk-deficient MEFs contain elevated phosphotyrosine levels of paxillin $(48,49)$. Using p52 ${ }^{\text {chk }}$ transfected Csk-deficient MEFs, we and others (31) observed Chk reduction of paxillin phosphotyrosine content. Regulation of paxillin phosphotyrosine content also appears dependent on the level of Chk expression. We postulate that Chk appears to have the following role in vivo: Src binds the proline-rich region of paxillin via its $\mathrm{SH} 3$ domain (50) and subsequently phosphorylates paxillin (47). Paxillin may also be phosphorylated by a third protein, FAK for example (47), thereby creating an $\mathrm{SH} 2$ binding site for $\operatorname{Src}(47,51)$ which further phosphorylates paxillin. Chk binds the newly and/or additionally phosphorylated paxillin. Following binding, Chk inactivates Src by phosphorylation. Ultimately, levels of tyrosine phosphorylated paxillin are reduced. Paxillin probably acts as an adapter molecule, tethering Chk and Src in close proximity, thereby facilitating Chk phosphorylation and subsequent inactivation of Src.
Paxillin is a predominantly cytoskeletal protein that localizes at focal plaques (52). Paxillin was originally identified in Rous sarcoma virus-transformed chick embryo fibroblasts (34). cDNA cloning of human and chicken paxillin has revealed their primary structure. Paxillin has a multitude of protein-protein interaction motifs, including several $\mathrm{SH} 2$ and $\mathrm{SH} 3$ binding motifs and four double-zinc finger LIM domains (53). Paxillin also contains five novel protein-binding repeats termed LD motifs, two of which bind vinculin and FAK (54). Paxillin binds to the c-Src SH3 domain (50). Whereas, tyrosine phosphorylated paxillin binds the $\mathrm{SH} 2$ domains of Crk, Crkl, C-Src, Lck, and Csk (39, 47, 51, 55, 56). In addition, proteins such as FAK, Pyk2, v-Crk, $\mathrm{v}$-Src, p210 ${ }^{\mathrm{Bcr} / \mathrm{Abl}}$ and $\mathrm{v}$-A bl have been shown to tyrosine phosphorylate paxillin $(39,47,56-58)$. Diverse stimuli such as bioactive lipids, neuropeptides, hormones, growth factors, and extracellular matrix proteins cause significant changes in paxillin phosphorylation (59). Chk, therefore, may play an important role in mediating the effects of the respective stimuli.

In summary, Chk via its $\mathrm{SH} 2$ domain directly binds tyrosine phosphorylated paxillin. Chk expression reduces phosphotyrosine levels of paxillin, demonstrating a potential biological role for Chk. Still unknown is the role of Chk in signaling. The interaction of Chk with paxillin furthers studies involving other potentially associated proteins. These studies provide insight into the role of Chk in tyrosine mediated signaling, as well as T cell physiology.

\section{REFERENCES}

1. Cooper, J. A. (1990) in Peptides and Protein Phosphorylation (Kemp, B. E., Ed.), pp. 85-113, CRC Press: Boca Raton, FL.

2. Bolen, J. B., Rowley, R. B., Spana, C., and Tsygankov, A. Y. (1992) FASEB J . 6, 3403-3409.

3. Courtneidge, S. A. (1985) EMBO J . 4, 1471-1477.

4. Reynolds, A. B., Vila, J ., Lansing, T. J ., Potts, W. M., Weber, M. J ., and Parsons, J. T. (1987) EMBO J . 6, 2359-2364.

5. Okada, M., and Nakagawa, H. (1989) J . Biol. Chem. 264, 2088620893.

6. Okada, M., Nada, S., Yamanashi, Y., Yamamoto, T., and Nakagawa, H. (1991) J . Biol. Chem. 266, 24249-24252.

7. Nada, S., Okada, M., MacAuley, A., Cooper, J. A., and Nakagawa, H. (1991) Nature 351, 69-72.

8. Bergman, M., Mustelin, T., Oetken, C., Partanen, J ., Flint, N. A., Amrein, K. E., Autero, M., Burn, P., and Alitalo, K. (1992) EMBO J. 11, 2919-2924.

9. Sabe, H., Knudsen, B., Okada, M., Nada, S., Nakagawa, H., and Hanafusa, H. (1992) Proc. Natl. Acad. Sci. U. S. A. 89, 2190 2194.

10. Imamoto, A., and Soriano, P. (1993) Cell 73, 1117-1124.

11. Nada, S., Yagi, T., Takeda, H., Tokunaga, T., Nakagawa, H., I kawa, Y., Okada, M., and Aizawa, S. (1993) Cell 73, 1125-1135.

12. Chow, L. M. L., J arvis, C., Hu, Q., Nye, S. H., Gervais, F. G., Veillette, A., and Matis, L. A. (1994) Proc. Natl. Acad. Sci. U. S. A. 91, 4975- 4979.

13. Klages, S., Adam, D., Class, K., Fargnoli, J ., Bolen, J . B., and 
Penhallow, R. C. (1994) Proc. Natl. Acad. Sci. U. S. A. 91, 2597-2601.

14. McVicar, D. W., Lal, B. K., Lloyd, A., Kawamura, M., Chen, Y. Q., Zhang, X. Y., Staples, J . E., Ortaldo, J . R., and O'Shea, J .J . (1994) Oncogene 9, 2037-2044.

15. Sakano, S., I wama, A., Inzawa, J ., Ariama, T., Ohno, M., and Suda, T. (1994) Oncogene 9, 1155-1161.

16. Bennett, B. D., Cowley, S., Jiang, S., London, R., Deng, B., Grabarek, J., Groopman, J . E., Goeddel, D. V., and Avraham, H. (1994) J . Biol. Chem. 269, 1068-1074.

17. Kuo, S. S., Moran, P., Gripp, J ., Armanini, M., Phillips, H. S., Goddard, A., and Caras, I. W. (1994) J . Neurosci. Res. 38, 705715.

18. Chow, L. M. L., Davidson, D., Fournel, M., Gosselin, P., Lemieux, S., Lyu, M. S., Kozak, C. A., Matis, L. A., and Veillette, A. (1994) Oncogene 9, 3437-3448.

19. Brauninger, A., Karn, T., Strebhardt, K., and RubsamenWaigmann, H. (1993) Oncogene 8, 1365-1369.

20. Avraham, S., J iang, S., Ota, S., Fu, Y., Deng, B., Dowler, L. L., White, R. A., and Avraham, H. (1995) J . Biol. Chem. 270, 18331842.

21. Hirao, A., Hamaguchia, I., Suda, T., and Yamaguchi, N. (1997) EMBO J. 16, 2342-2351.

22. Musso, T., Varesio, L., Zhang, X. Y., Rowe, T. K., Ferrara, P., Ortaldo, J . R., O'Shea, J . J ., and McVicar, D. W. (1994) J . Exp. Med. 180, 2383-2388.

23. Grgurevich, S., Linnekin, D., Musso, T., Zhang, X. Y., Modi, W., Varesio, L., Ruscetti, F. W., Ortaldo, J. R., and McVicar, D. W. (1997) Growth Factors 14, 103-115.

24. Weiss, A. and Littman, D. R. (1994) Cell 76, 263-294.

25. Abraham, N., Miceli, M. C., Parnes, J . C., and Veillette, A. (1991) Nature 350, 62- 66.

26. Cooke, M. P., Abraham, K. M., Forbush, K. A., and Perlmutter, R. M. (1991) Cell 65, 281-291.

27. Molina, T. J., Kishihara, K., Siderovski, D. P., van Ewijk, W., Narendran, A., Timms, E., Wakeham, A., Paige, C. J., Hartmann, K. U., Veillette, A., Davidson, D., and Mak, T. W. (1992) Nature 357, 161-164.

28. Chow, L. M. L., Fournel, M., Davidson, D., and Veillette, A. (1993) Nature 365, 156-160.

29. Cloutier, J .-F., Chow, L. M. L., and Veillette, A. (1995) Mol. Cell. Biol. 15, 5937-5944.

30. Zhang, X. Y., Mikhael, A., O'Shea, J . J ., Ortaldo, J. R., and McVicar, D. W. J . Biol. Chem. (submitted).

31. Davidson, D., Chow, L. M. L., and Veillette, A. (1997) J . Biol. Chem. 272, 1355- 1362.

32. Pawson, T. and Gish, G. D. (1992) Cell 71, 359-362.

33. Cicchetti, P., Mayer, B. J ., Thiel, G., and Baltimore, D. (1992) Science 257, 803-806.

34. Glenney, J . R., and Zokas, L. (1989) J . Cell Biol . 108, 2401-2408.

35. Ortaldo, J. R., Mason, A., and Overton, R. (1986) J . Exp. Med. 164, 1193-1205.

36. O'Shea, J. J., McVicar, D. W., Bailey, T. L., Burns, C., and
Smyth, M. J . (1992) Proc. Natl. Acad. Sci. U. S. A. 89, 1030610310.

37. O'Shea, J . J ., McVicar, D. W., Kuhns, D. B., and Ortaldo, J . R. (1992) J . Immunol. 148, 2497-2503.

38. Deng, W. P. and Nickoloff, J . A. (1992) Anal. Biochem. 200, 81.

39. Sabe, H., Hata, A., Okada, M., Nakagawa, H., and Hanafusa, H. (1994) Proc. Natl. Acad. Sci. U. S. A. 91, 3984-3988.

40. Marengere, L. E. M. and Pawson, T. (1992) J . Biol. Chem. 267, 22779-22786.

41. Mayer, B. J , J ackson, P. K., Van Etten, R. A., and Baltimore, D. (1992) Mol. Cell. Biol. 12, 609-618.

42. J hun, B. H., Rivnay, B., Price, D., and Avraham, H. (1995) J . Biol. Chem. 270, 9661-9666.

43. Zrihan-Licht, S., Lim, J ., Keydar, I., Sliwkowski, M. X., Groopman, J . E., and Avraham, H. (1997) J . Biol. Chem. 272, 18561863.

44. Hirao, A., Huang, X. L., Suda, T., and Yamaguchi, N. (1998) J. Biol. Chem. 273, 10004-10010.

45. Waksman, G., Shoelson, S. E., Pant, N., Cowburn, D., and Kuriyan, J . (1993) Cell 72, 779-790.

46. Waksman, G., Kominos, D., Robertson, S. R., Pant, N., Baltimore, D., Birge, R. B., Cowburn, D., Hanafusa, H., Mayer, B. J ., Overduin, M., Resh, M. D., Rios, C. B., Silverman,, L., and Kuriyan, J . (1992) Nature 358, 646-653.

47. Schaller, M. D. and Parsons, J. T. (1995) Mol. Cell. Biol. 15, 2635-2645.

48. Nada, S., Okada, M., Aizawa, S., and Nakagawa, H. (1994) Oncogene 9, 3571-3578.

49. Thomas, S. M., Soriano, P., and I mamoto, A. (1995) Nature 376, 267-271.

50. Weng, Z., Taylor, J . A., Turner, C. E., Brugge, J . S., and SeidelDugan, C. (1993) J . Biol. Chem. 268, 14956-14963.

51. Ostergaard, H. L., Lou, O., Arendt, C. W., and Berg, N. N. (1998) J . Biol. Chem. 273, 5692-5696.

52. Turner, C. E., Glenney, J . R., and Burridge, K. (1990) J . Cell Biol. 111, 1059-1068.

53. Turner, C. E. and Miller, J . T. (1994) J . Cell Sci. 107, 1583-1591.

54. Brown, M. C., Perotta, J . A., and Turner, C. E. (1996) J . Cell Biol. 135, 1109-1123.

55. Salgia, R., Uemura, N., Okuda, K., Li, J . L., Pisick, E., Sattler, M., de J ong, R., Druker, B., Heisterkamp, N., Chen, L. B., Groffen, J ., and Griffin, J . D. (1995) J . Biol. Chem. 270, 29145-29150.

56. Birge, R. B., Fajardo, J . E., Reichman, C., Shoelson, S. E., Songyang, Z., Cantley, L. C., and Hanafusa, H. (1993) Mol. Cell. Biol. 108, 4648- 4656.

57. Salgia, R., Brunkhorst, B., Pisick, E., Li, J . L., Lo, S. H., Chen, L. B., and Griffin, J. D. (1995) Oncogene 11, 1149-1155.

58. Salgia, R., Avraham, S., Pisick, E., Li, J . L., Raja, S., Greenfield, E. A., Sattler, M., Avraham, H., and Griffin, J . D. (1996) J . Biol. Chem. 271, 31222-31226.

59. Rozengurt, E. (1995) Cancer Surveys 24, 81-96. 